\title{
EFICÁCIA DE HERBICIDAS NO CONTROLE DE PLANTAS DANINHAS NA CULTURA DA CEBOLA EM SEMEADURA DIRETA ${ }^{1,2}$
}

\author{
LINO R. FERREIRA ${ }^{3}$, JULIO C. DURIGAN ${ }^{4}$ e MANUEL G. C. CHURATA-MASCA ${ }^{4}$
}

\section{RESUMO}

As plantas de cebola provenientes da semeadura direta no campo são mais danificadas pelo cultivo mecânico e são mais sensíveis aos herbicidas, principalmente os latifolicidas, do que quando transplantadas. Com o objetivo de avaliar a eficácia dos herbicidas oxyfluorfen, ioxyniloctanoato e fluazifop-p-butil, aplicados em pósemergência, isoladamente ou em mistura no tanque, com ou sem aplicação de paraquat, antes da emergência das plantas de cebola, conduziu-se este trabalho no município de Monte Alto, SP. Nenhum dos herbicidas aplicados isoladamente foi eficiente no controle de todas as espécies daninhas presentes na área experimental. As misturas no tanque de fluazifop-p-butil com oxyfluorfen ou ioxynil-octanoato, independente da aplicação ou não de paraquat aos cinco dias após a semeadura, controlaram eficientemente Portulaca oleracea, Amaranthus lividus, Echinochloa crusgalli, Eragrostis pilosa, Digitaria horizontalis, Eleusine indica e Brachiaria plantaginea, com produção de bulbos semelhante à da testemunha capinada.

Palavras chave: Allium cepaparaquat, oxyfluorfen, ioxynil-octanoato, fluazifop-p-butil.

\section{ABSTRACT \\ Efficacy of herbicides on weed control in onion direct sowing}

Onion plants, from direct sowing to the field, are more damaged by mechanical cultivation and more sensitive to herbicides, especially to broadleaf herbicides, than transplanted onions. With the purpose of evaluating the efficacy of the herbicides oxyfluorfen, ioxynyl-octanoato and fluazifop-p-butyl, applied in post-emergence, alone or tank mix, with or without paraquat application, before onion plants emergence, this investigation was carried out at Monte Alto County, São Paulo State, Brazil. None of the herbicides sprayed alone were efficient in the control of all the weeds present in the experimental area. The tank mix of fluazifop-p-butyl plus oxyfluorfen or ioxynyloctanoato, regardless of paraquat application, at five days after sowing, controlled efficiently Portulaca oleracea, Amaranthus lividus, Echinoclhoa crusgalli, Eragrostis pilosa, Digitaria horizontalis, Eleusine indica and Brachiaria plantaginea, with production of bulbs similar to the weeded control.

Key words: Allium cepa, paraquat; oxyfluorfen, ioxynyl-octanoato, fluazifop-p-butil.

\section{INTRODUÇÃO}

A cultura da cebola é muito sensível das folhas cilíndricas, do porte baixo e do lento desenvolvimento inicial (Shadbolt \& Holm, 1956), características essas que à interferência das plantas infestantes, principalmente por causa da disposição ereta

\footnotetext{
${ }^{1}$ Recebido para publicação em 20/02/98 e na forma revisada em 30/07/98.

2 Parte da tese do primeiro autor apresentada à FCAVJ/UNESP para obtenção do título de Doutor em Agronomia.

3 Prof $^{\circ}$ do Departamento de Fitotecnia da UFV. CEP 36571-000, Viçosa/MG.

${ }^{4}$ Professores da FCAVJ/UNESP. CEP 14870-000, Jaboticabal/SP.
} 
sombreamento do solo, com baixo poder competitivo, permitindo a germinação de plantas infestantes durante todo ciclo da cultura.

No sistema de semeadura direta, a interferência das plantas daninhas é, ainda, mais drástica, uma vez que, durante o estabelecimento da planta no campo, a capacidade competitiva da mesma é muito pequena (Vorobiov e Vasets'kii, 1984, citados por Pitelli, 1987). Neste sistema as plantas são mais danificadas pelo cultivo mecânico e, também, são mais sensíveis aos herbicidas, principalmente aqueles com ação sobre plantas daninhas do tipo folha larga, quando aplicados nos estádios iniciais de desenvolvimento.

Poucos são os herbicidas recomendados para a cultura transplantada que podem ser usados no sistema de semeadura direta, em razão da maior sensibilidade das plantas de cebola em início de desenvolvimento. Alguns herbicidas como fluazifop-p-butil, sethoxydim, oxyfluorfen e ioxynil-octanoato tem apresentado resultados promissores, quando usados em doses reduzidas (Leal et al., 1985, Oliveira Junior et al., 1995 e 1997, Ferreira, 1997). No município de Monte Alto, SP, alguns produtores de cebola têm utilizado o paraquat, aplicado cinco dias após a semeadura, porém antes da emergência das plantas de cebola, seguindo-se duas aplic ações da mistura no tanque de oxyfluorfen + fluazifop-p-butil, sendo uma aplicação aos 20 e a outra entre 35 e 45 dias após a semeadura.

O objetivo deste trabalho foi o de avaliar a eficácia dos herbicidas oxyfluorfen, ioxyniloctanoato e fluazifop-p-butil aplicados em pósemergência, em áreas de semeadura direta de cebola, isolados ou em misturas, com e sem aplicação de paraquat antes da emergência das plântulas de cebola, no controle de plantas daninhas, bem como medir seus efeitos na produção e qualidade de bulbos.

\section{MATERIAL E MÉTODOS}

O experimento foi conduzido no período de 24/04 a 15/09/94, num solo de textura argilosa com $0,9 \%$ de matéria orgânica, na região produtora de cebola, município de Monte Alto, SP, com latitude sul de $21^{\circ} 15^{\prime}$, latitude oeste de $48^{\circ} 29^{\prime}$ e altitude de $720 \mathrm{~m}$.

$\mathrm{O}$ delineamento experimental utilizado foi o de blocos casualizados, com quatro repetições, num esquema fatorial $(5 \times 2+2)$, com os tratamentos assim designados: paraquat nas doses de 0,0 e $0,100 \mathrm{~kg}$ i. a. /ha, seguidas de oxyfluorfen a $0,048 \mathrm{~kg}$ i. a./ha, ioxynil-octanoato a $0,200 \mathrm{~kg}$ i. a./ha, fluazifop-p-butil a $0,100 \mathrm{~kg}$ i. a./ha, fluazifop-p-butil a $0,100 \mathrm{~kg}$ i. a./ha + oxyfluorfen a $0,048 \mathrm{~kg}$ i. a./ha e fluazifop-p-butil a $0,100 \mathrm{~kg}$ i. a./ha + ioxyniloctanoato a $0,200 \mathrm{~kg}$ i. a./ha. Além desses tratamentos foram adicionadas duas testemunhas, com e sem capinas.

Cada parcela experimental foi constituída de um canteiro de 1,2 $\mathrm{m}$ de largura por 5,0 $\mathrm{m}$ de comprimento. $\mathrm{O}$ espaçamento entre canteiros foi de $0,3 \mathrm{~m}$. Foram consideradas como área útil as duas fileiras centrais, eliminando-se $0,5 \mathrm{~m}$ de cada extremidade. A semeadura do cultivar Granex Ouro foi feita no dia 24 de abril de 1994 em quatro fileiras, espaçadas de $0,3 \mathrm{~m}$, com uma densidade de 40 sementes por metro de sulco $(2,4$ $\mathrm{kg} / \mathrm{ha}$ ).

A adubação de plantio foi $1700 \mathrm{~kg} / \mathrm{ha}$ de Cooperhumus $470 \mathrm{BZ}$, cuja formulação contém: $4 \%$ de nitrogênio total, $6 \%$ de $\mathrm{K}_{2} \mathrm{O}$ solúvel em $\mathrm{H}_{2} \mathrm{O}, 12 \%$ de $\mathrm{P}_{2} \mathrm{O}_{5}$ solúvel em CNA $+\mathrm{H}_{2} \mathrm{O}, 0,15 \%$ de $\mathrm{Zn}, 0,05 \%$ de B, $25 \%$ de matéria orgânica total. Foram feitas seis adubações em cobertura, sendo a primeira realizada 20 dias após a semeadura (DAS) com $124 \mathrm{~kg} / \mathrm{ha}$ de nitrocálcio, a segunda aos 36 DAS com $145 \mathrm{~kg} / \mathrm{ha}$ de sulfato de amônio e as demais com $150 \mathrm{~kg} / \mathrm{h}$ a da fórmula 12 06-12, respectivamente aos 55, 86 e 106 DAS.

As aplicações dos herbicidas foram feitas com um pulverizador costal, munido de barra de três bicos de jato plano ("leque") 11003 , espaçados de $0,5 \mathrm{~m}$, à pressão constante de $2,1 \mathrm{kgf} / \mathrm{cm}^{2}$, mantida pelo $\mathrm{CO}_{2}$ comprimido, proporcionando um consumo de calda equivalente a $300 \mathrm{l} / \mathrm{ha}$. O paraquat foi aplicado antes da emergência das plantas de cebola, aos cinco dias após a semeadura. Os demais herbicidas foram aplicados aos 18 DAS, nas parcelas sem paraquat, quando as plantas de cebola estavam com duas folhase, 
aproximadamente, $5,5 \mathrm{~cm}$ de altura. As plantas daninhas dicotiledôneas estavam, em média, com até $4 \mathrm{~cm}$ de altura e as gramíneas com até quatro perfilhos. Nas parcelas com paraquat, a aplicação dos demais herbicidas foi realizada aos 26 DAS, quando as plantas de cebola estavam com duas a três folhas e com altura média de $10 \mathrm{~cm}$. As plantas daninhas, nesta época, apresentavam estádios semelhantes aos das parcelas sem paraquat aos 18 DAS.

Devido ao fato do experimento ser instalado no meio de uma lavoura de aproximadamente 20 ha de cebola, irrigada por pivô central, todos os tratos culturais, do plantio à colheita, foram executados à maneira do produtor, exceto as capinas, que foram feitas apenas na testemunha capinada, arrancando-se as plantas daninhas, manualmente, a cada quinze dias.

A porcentagem de controle, em relação à testemunha sem capina, do total da plantas daninhas foi avaliada aos 36; 58; 101 e 138 DAS. O número de plantas daninhas, por espécie, foi avaliado aos 58 DAS. Para amostragem das plantas daninhas utilizou-se três retângulos $(0,2 \mathrm{x}$ $0,5 \mathrm{~m}$ ) por parcela, ao acaso.

O estande da cultura foi avaliado aos 17; 43; 74 e 138 DAS. Foram contados o número de plantas de cebola em $2 \mathrm{~m}$ das linhas centrais, sempre na mesma área, em todas as avaliações. A biomassa seca das plantas de cebola foi avaliada aos 30; 60 e 90 DAS. As plantas foram arrancadas, lavadas e secas à temperatura de $70 \pm$ $2^{\circ} \mathrm{C}$, até peso constante. Foram coletadas dez plantas por amostragem na área da parcela reservada para este fim.

A colheita foi realizada aos 138 DAS, em $2 \mathrm{~m}$ das fileiras centrais, conforme recomendações técnicas para a cultura. Após a cura fez-se a limpeza, a classificação dos bulbos, conforme o diâmetro horizontal e a pesagem dos mesmos (Brasil, 1982). Foram considerados para análise estatística a produção total, a produção e o peso médio de bulbos comercializáveis (produção total excluindo-se bulbos com diâmetros menores do que $20 \mathrm{~mm}$ ).
Fez-se a análise de variância dos tratamentos. Em seguida, desdobrou-se a interação, mesmo quando $\mathrm{F}$ foi não significativo. Os efeitos da aplicação de paraquat (com e sem paraquat) em cada herbicida, aplicado em pósemergência das plantas de cebola, sobre as características avaliadas foram comparados pelo teste $\mathrm{F}$ a $5 \%$ de probabilidade, enquanto que os efeitos dos herbicidas aplicados em pósemergência das plantas de cebola, nas parcelas com ou sem paraquat, foram comparados pelo teste de Tukey a 5\% de probabilidade. As médias das testemunhas com e sem capina foram comparadas pelo teste $\mathrm{F}$ a $5 \%$ de probabilidade. Para comparar as médias da testemunha capinada com as médias de cada tratamento do fatorial, utilizou-se o teste de Dunnet a 5\% de probabilidade (Banzatto \& Kronka, 1992).

\section{RESULTADOS E DISCUSSÃO}

As plantas daninhas que ocorreram no local deste experimento foram: Portulaca oleracea, Amaranthus lividus, Echinochloa crusgalli, Eragrostis pilosa, Digitaria horizontalis, Eleusine indica e Brachiaria plantaginea (Tabela 1). Os tratamentos com oxyfluorfen e ioxynil-octanoato, aplicados isolados ou em mistura no tanque com fluazifop-pbutil, apresentaram os menores números de $P$. oleracea e $A$. lividus, exceto fluazifop-p-butil + ioxynil-octanoato, nas parcelas sem paraquat, cujo número de $P$. oleracea não diferiu do obtido com fluazifop-p-butil aplicado isoladamente. Os menores números de E. crusgalli, E. pilosa, D. horizontalis, E. indica e B. plantaginea foram obtidos com fluazifop-p-butil, aplicado isoladamente ou em mistura no tanque com oxyfluorfen ou ioxynil-octanoato, exceto para $E$. pilosa e B. plantaginea nos tratamentos com paraquat. Não houve efeito da aplicação de paraquat para fluazifop-p-butil, quando este foi aplicado isoladamente, ou em mistura de tanque com oxyfluorfen, sobre nenhuma das plantas daninhas avaliadas. Houve efeito positivo da aplicação de paraquat para oxyfluorfen sobre o número de $E$. crusgalli, E. pilosa e $B$. 
TABELA 1. Números médios de Portulaca oleracea (POROL), Amaranthus lividus (AMALI), Echinochloa crusgalli (ECHCG), Eragrostis pilosa (ERAPI), Digitaria horizontalis (DIGHO), Eleusine indica (ELEIN), Brachiaria plantaginea (BRAPL) e do total das plantas daninhas aos 58 dias após a semeadura (DAS) da cebola cv. Granex Ouro. Monte Alto, 1994.

\begin{tabular}{|c|c|c|c|c|c|c|c|c|c|}
\hline \multirow{2}{*}{$\begin{array}{l}\text { Tratamentos } \\
\text { Aplicação } \\
\text { de Paraquat }\end{array}$} & \multirow{2}{*}{$\frac{\left(\text { Doses }{ }^{\backslash 1} \text { e Épocas de Aplicação }{ }^{12} \text { ) }\right.}{\text { Aplicação de Pós-emergentes }}$} & \multicolumn{8}{|c|}{ Número de Plantas $/ \mathrm{m}^{2} \underline{13}, \underline{4}, \underline{5}$} \\
\hline & & POROL & AMALI & ECHCG & ERAPI & DIGHO & ELEIN & BRAPL & Total \\
\hline Sem & Oxyfluorfen & $0,0 \mathrm{c}$ & $0,0 \mathrm{~b}$ & $9,1 \mathrm{aA}$ & $15,1 \mathrm{aA}$ & $10,6 \mathrm{~b}$ & $15,2 \mathrm{a}$ & $4,9 \mathrm{aA}$ & $61,6 \mathrm{aA}$ \\
\hline \multirow[t]{4}{*}{ Paraquat } & Fluazifop-p-butil & $17,4 \mathrm{a}$ & $5,3 \mathrm{a}$ & $0,0 \mathrm{~b}$ & $0,0 \mathrm{~b}$ & $0,5 \mathrm{c}$ & $0,0 \mathrm{~b}$ & $0,0 \mathrm{~b}$ & $24,1 \mathrm{~b}$ \\
\hline & Fluazifop-p-butil + oxyfluorfen & $0,0 \mathrm{c}$ & $0,0 \mathrm{~b}$ & $0,0 \mathrm{~b}$ & $0,0 \mathrm{~b}$ & $0,0 \mathrm{c}$ & $0,0 \mathrm{~b}$ & $0,0 \mathrm{~b}$ & $0,0 \mathrm{~d}$ \\
\hline & Ioxynil-octanoato & $1,3 \mathrm{bc}$ & $0,0 \mathrm{~b}$ & $14,4 \mathrm{aA}$ & $2,8 \mathrm{~b}$ & $42,7 \mathrm{aA}$ & $17,4 \mathrm{a}$ & 4,9 a & $88,2 \mathrm{aA}$ \\
\hline & Fluazifop-p-butil + ioxynil-octanoato & $7,4 \mathrm{abA}$ & $0,0 \mathrm{~b}$ & $0,0 \mathrm{~b}$ & $0,0 \mathrm{~b}$ & $0,0 \mathrm{c}$ & $0,5 \mathrm{~b}$ & $0,0 \mathrm{~b}$ & $8,5 \mathrm{cA}$ \\
\hline Com & Oxyfluorfen & $0,0 \mathrm{~b}$ & $0,0 \mathrm{~b}$ & $2,2 \mathrm{abB}$ & $0,0 \mathrm{~B}$ & $11,2 \mathrm{a}$ & $12,4 \mathrm{a}$ & $0,5 \mathrm{~B}$ & $27,4 \mathrm{bB}$ \\
\hline \multirow[t]{4}{*}{ Paraquat } & Fluazifop-p-butil & 10,4 a & 4,9 a & $0,0 \mathrm{~b}$ & 0,0 & $0,0 \mathrm{~b}$ & $0,0 \mathrm{~b}$ & 0,0 & $15,5 \mathrm{~b}$ \\
\hline & Fluazifop-p-butil + oxyfluorfen & $0,0 \mathrm{~b}$ & $0,0 \mathrm{~b}$ & $0,0 \mathrm{~b}$ & 0,0 & $0,0 \mathrm{~b}$ & $0,0 \mathrm{~b}$ & 0,0 & $0,0 \mathrm{c}$ \\
\hline & Ioxynil-octanoato & $0,0 \mathrm{~b}$ & $0,0 \mathrm{~b}$ & $6,0 \mathrm{aB}$ & 2,8 & $25,7 \mathrm{aB}$ & $17,0 \mathrm{a}$ & 2,2 & $59,9 \mathrm{aB}$ \\
\hline & Fluazifop-p-butil + ioxynil-octanoato & $1,3 \mathrm{bB}$ & $0,0 \mathrm{~b}$ & $0,0 \mathrm{~b}$ & 0,0 & $0,0 \mathrm{~b}$ & $0,0 \mathrm{~b}$ & 0,0 & $1,3 \mathrm{cB}$ \\
\hline \multicolumn{2}{|c|}{ Testemunha sem capinas } & 28,5 & 4,9 & 3,9 & 5,3 & 28,5 & 22,3 & 5,5 & 87,1 \\
\hline \multicolumn{2}{|l|}{$\mathrm{CV}(\%)$} & 40,7 & 26,2 & 53,1 & 71,5 & 35,9 & 21,4 & 38,6 & 17,1 \\
\hline
\end{tabular}

11 Paraquat $=0,0$ e 0,100; oxyfluorfen $=0,048$; ioxynil-octanoato $=0,200$ e fluazifop-p-butil $=0,100$ (kg i.a. $/ \mathrm{ha}$ ).

12 Aplicação de paraquat realizada aos 5 dias após a semeadura (DAS), em pós-emergência das plantas daninhas e pré-emergência das plantas de cebola; aplicação de pós-emergentes realizada 18 e 26 DAS, respectivamente para as parcelas sem e com paraquat.

13 Letras minúsculas comparam as médias dos herbicidas pós-emergentes, com ou sem paraquat, pelo teste de Tukey a $5 \%$ de probabilidade.

14 Letras maiúsculas comparam cada herbicida pós-emergente, sem e com paraquat, pelo teste $\mathrm{F}$ a $5 \%$ de probabilidade.

15 Ausência de letras nas colunas indica não significância dos dados. 
plantaginea; para ioxynil-octanoato sobre o número de $E$. crusgalli e $D$. horizontalis e para fluazifop-p-butil + ioxynil-octanoato sobre $P$. oleracea. A aplicação prévia de paraquat também reduziu o número total de plantas daninhas nos tratamentos com oxyfluorfen quando este foi aplicado isoladamente e com ioxynil-octanoato, tanto isolado quanto em mistura com fluazifop-pbutil.

Houve efeito da aplicação dos herbicidas pós-emergentes, tanto na presença quanto na ausência de paraquat, para porcentagem de controle, em todas as épocas de avaliação (Tabela 2). Os melhores controles das plantas daninhas foram obtidos com as misturas no tanque de fluazifop-p-butil com oxyfluorfen ou ioxyniloctanoato, atingindo na época da colheita (138 DAS) controle superior a $83 \%$ em todas as misturas, exceto para fluazifop-p-butil + ioxyniloctanoato nas parcelas sem paraquat. Os herbicidas aplicados isoladamente não proporcionaram bom controle das plantas daninhas, sendo a porcentagem de controle menor, quanto mais próximo da colheita. Houve efeito benéfico da aplicação de paraquat para o ioxyniloctanoato até aos 58 DAS e para o oxyfluorfen até aos 101 DAS. Na época da colheita apenas o efeito do fluazifop-p-butil, aplicado isoladamente ou em mistura com ioxynil-octanoato, foi beneficiado pela aplicação de paraquat.

Considerando que os herbicidas foram usados em doses reduzidas, esperava-se uma reinfestação da área, mesmo nas parcelas que apresentaram excelente controle inicial, conforme observou Oliveira Junior (1994). Tal fato não ocorreu, o que dispensou a aplicação de mais uma dose de herbicidas, conforme é tradicionalmente feita pelos agricultores da região. Essa é uma das vantagens do parcelamento da dose dos herbicidas, que permite economia de produto, se não houver reinfestação, além de aumentar a tolerância das plantas de cebola aos herbicidas (Ferreira, 1997).

Houve efeito da aplicação de pósemergentes sobre a porcentagem de redução de estande apenas na ausência de paraquat nas duas épocas de avaliação (Tabela 3). Aos 43 DAS, as maiores reduções foram obtidas com oxyfluorfen e ioxynil-octanoato e aos 138 DAS com ioxyniloctanoato. Nas duas avaliações, os tratamentos que apresentaram os piores controles das plantas daninhas foram, também, os que proporcionaram as maiores reduções no estande. Houve efeito da aplicação de paraquat apenas para o ioxyniloctanoato, aplicado isoladamente, cuja maior redução do estande ocorreu nas parcelas sem paraquat. Aos 138 DAS, houve diferença entre as testemunhas com capina e sem capina e entre a testemunha capinada e os tratamentos com oxyfluorfen e ioxynil-octanoato, ambos aplicados isoladamente, indicando que nesse experimento a redução do estande foi devido à interferência das plantas daninhas com as plantas de cebola. Leal (1984), Oliveira (1989) e Oliveira Junior (1994), também observaram redução de estande com aumento da interferência das plantas daninhas sobre a cebola no sistema de semeadura direta. As misturas de fluazifop-p-butil + oxyfluorfen, sem ou com paraquat e fluazifop-p-butil + ioxyniloctanoato, com paraquat, não influenciaram o estande, quando comparados à testemunha capinada.

Quanto a biomassa seca das plantas de cebola (Tabela 4), não houve diferença entre tratamentos, até a avaliação realizada aos 60 DAS, indicando, mais uma vez, a baixa toxicidade dos herbicidas nas doses avaliadas. Aos 90 DAS, houve efeito da aplicação de pósemergentes, para as parcelas sem paraquat, cuja maior biomassa foi obtida com fluazifop-p-butil, isolado ou em mistura com ioxynil-octanoato, os quais diferiram apenas do ioxynil-octanoato aplicado isoladamente. Houve efeito da aplicação de paraquat apenas para o oxyfluorfen, sendo a maior biomassa obtida nas parcelas com aplicação prévia do paraquat. A testemunha capinada proporcionou maior acúmulo de biomassa que a testemunha sem capina, tornandose evidente a interferência das plantas daninhas sobre a cultura. A testemunha capinada também proporcionou maior acúmulo de biomassa que o oxyfluorfen, na ausência de paraquat e que ioxynil-octanoato, tanto na presença quanto na ausência de paraquat, 
TABELA 2. Porcentagens médias de controle do total de plantas daninhas aos 36, 58, 101 e 138 dias após a semeadura (DAS) da cebola cv 'Granex Ouro'. Monte Alto, SP, 1994.

\begin{tabular}{|c|c|c|c|c|c|}
\hline \multicolumn{3}{|c|}{ Tratamentos (Doses $1 \underline{1}$ e Épocas de Aplicação 12 ) } & \multicolumn{3}{|c|}{ Porcentagem de Controle $\underline{13} ; \underline{4}, \underline{5}$} \\
\hline $\begin{array}{l}\text { Aplicação de } \\
\text { Paraquat }\end{array}$ & Aplicação de Pós-emergentes & 36 DAS & 58 DAS & $101 \mathrm{DAS}$ & $138 \mathrm{DAS}$ \\
\hline Sem & Oxyfluorfen & $47,0 \mathrm{bB}$ & $30,2 \mathrm{cB}$ & $13,7 \mathrm{cB}$ & $0,0 \mathrm{~b}$ \\
\hline \multirow[t]{4}{*}{ Paraquat } & Fluazifop-p-butil & $85,0 \mathrm{a}$ & $77,5 \mathrm{~b}$ & $56,2 \mathrm{~b}$ & $18,7 \mathrm{bB}$ \\
\hline & Fluazifop-p-butil + oxyfluorfen & $100,0 \mathrm{a}$ & $100,0 \mathrm{a}$ & 96,2 a & 83,7 a \\
\hline & Ioxynil-octanoato & $38,0 \mathrm{bB}$ & $23,0 \mathrm{cB}$ & $1,2 \mathrm{c}$ & $0,0 \mathrm{~b}$ \\
\hline & Fluazifop-p-butil + ioxynil-octanoato & 93,7 a & $87,2 \mathrm{ab}$ & 89,2 a & $67,5 \mathrm{aB}$ \\
\hline Com & Oxyfluorfen & $87,2 \mathrm{aA}$ & $78,0 \mathrm{abA}$ & $51,2 \mathrm{bA}$ & $10,0 \mathrm{c}$ \\
\hline \multirow[t]{4}{*}{ Paraquat } & Fluazifop-p-butil & 87,5 a & $81,0 \mathrm{a}$ & $67,5 \mathrm{~b}$ & $45,0 \mathrm{bA}$ \\
\hline & Fluazifop-p-butil + oxyfluorfen & $100,0 \mathrm{a}$ & $100,0 \mathrm{a}$ & 96,7 a & $83,7 \mathrm{a}$ \\
\hline & Ioxynil-octanoato & $66,0 \mathrm{bA}$ & $56,5 \mathrm{bA}$ & $5,0 \mathrm{c}$ & $0,0 \mathrm{c}$ \\
\hline & Fluazifop-p-butil + ioxynil-octanoato & $99,0 \mathrm{a}$ & 99,0 a & 94,0 a & $83,7 \mathrm{aA}$ \\
\hline \multicolumn{2}{|c|}{ Testemunha sem capina } & 0,0 & 0,0 & 0,0 & 0,0 \\
\hline \multicolumn{2}{|l|}{$\mathrm{CV}(\%)$} & 11,9 & 16,4 & 16,8 & 28,3 \\
\hline
\end{tabular}

11 Paraquat $=0,0$ e 0,100; oxyfluorfen $=0,048$; ioxynil-octanoato $=0,200$ e fluazifop-p-butil $=0,100$ ( $\mathrm{kg}$ i a./ha).

12 Aplicação de paraquat realizada aos 5 dias após a semeadura (DAS), em pós-emergência das plantas daninhas e pré-emergência das plantas de cebola; aplicação de pósemergentes realizada aos 18 e 26 DAS, respectivamente para as parcelas sem e com paraquat.

13 Letras minúsculas comparam as médias dos herbicidas pós-emergentes, com ou sem paraquat, pelo teste de Tukey a $5 \%$ de probabilidade.

14 Letras maiúsculas comparam cada herbicida pós-emergentes, sem e com paraquat, pelo teste $\mathrm{F}$ a $5 \%$ de probabilidade.

15 Ausência de letras nas colunas indica não significância dos dados. 
TABELA 3. Médias do estande inicial de cebola cv 'Granex Ouro', aos 17 dias após a semeadura (DAS) e da porcentagem de redução do mesmo, aos 43 e 138 DAS. Monte Alto, SP, 1994.

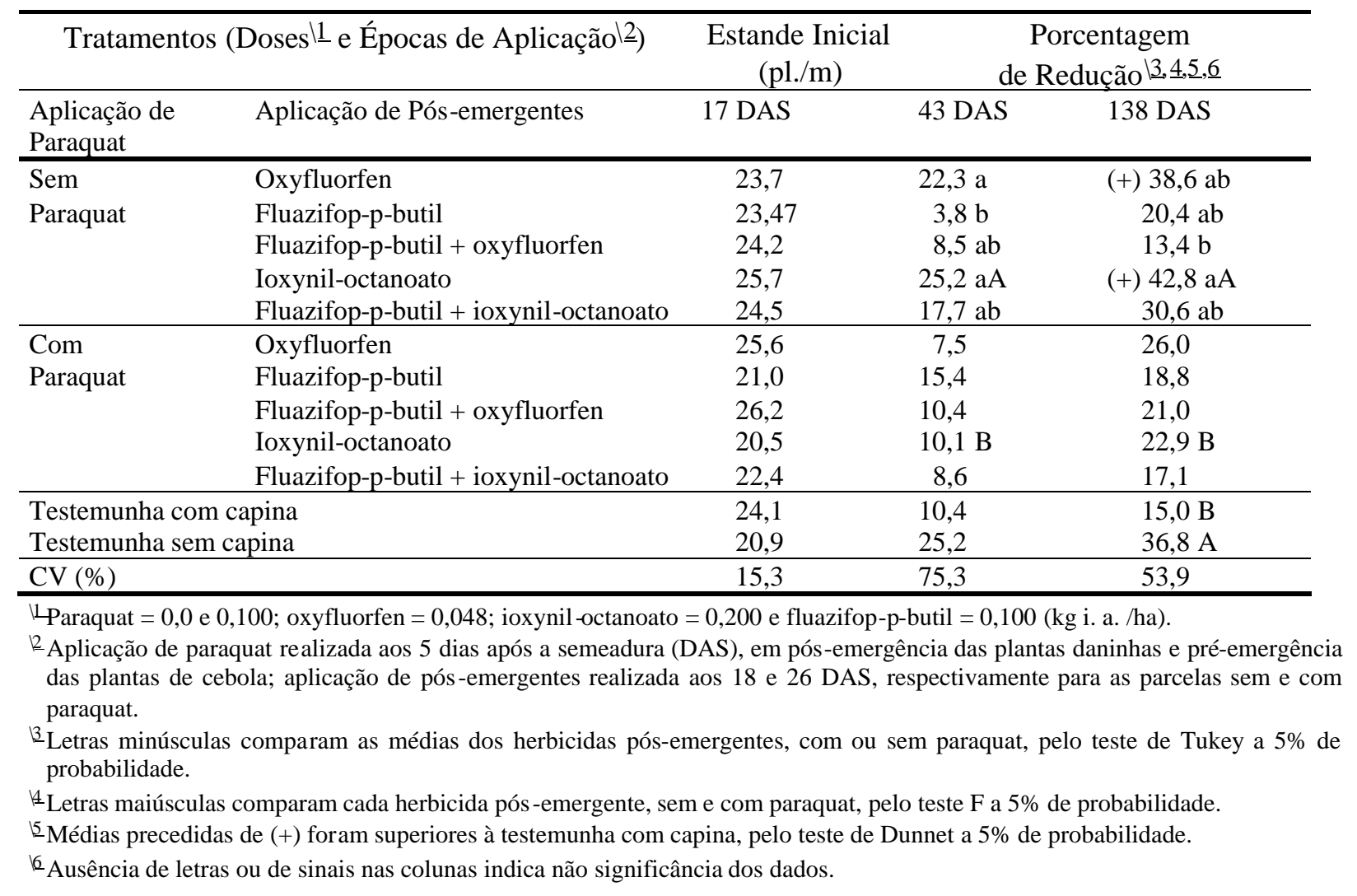

justamente os tratamentos que apresentaram os piores controles das plantas daninhas.

Houve efeito da aplicação de pósemergentes, tanto na presença quanto na ausência do paraquat, para a produção total, produção e peso médio de bulbos comercializáveis (Tabela 5). $\mathrm{Na}$ ausência do paraquat, as maiores produções foram obtidas com fluazifop-p-butil em mistura no tanque com oxyfluorfen ou ioxynil-octanoato e as menores com oxyfluorfen e ioxynil-octanoato, aplicados isoladamente. Na presença do paraquat, as maiores produções foram obtidas com fluazifop-p-butil + oxyfluorfen, que diferiram do ioxynil-octanoato e do fluazifop-p-butil aplicados isoladamente.

Houve efeito da aplicação de paraquat apenas para oxyfluorfen, cuja maior produção, tanto total quanto comercializável, foi obtida na presença do paraquat. O maior peso médio de bulbos, na ausência de paraquat, foi obtido com fluazifop-p-butil + ioxynil-octanoato, que não diferiu do obtido com fluazifop-p-butil + oxyfluorfen. Na presença de paraquat, os maiores pesos médios foram obtidos com as misturas de tanque de fluazifop-p-butil com oxyfluorfen ou ioxynil-octanoato, que diferiram apenas de ioxynil-octanoato aplicado isoladamente. As parcelas com oxyfluorfen, na ausência de paraquat e ioxynil-octanoato, tanto na presença quanto na ausência do paraquat, apresentaram produção total, produção e peso médio de bulbos comercializáveis inferiores aos obtidos na testemunha, sendo esses tratamentos os que, também, apresentaram os piores controles das plantas daninhas. A menor produção obtida com oxyfluorfen e ioxynil-octanoato, aplicados isoladamente, foi por causa do 
TABELA 4. Médias da biomassa seca de plantas de cebola cv 'Granex Ouro', aos 30, 60 e 90 dias após a semeadura (DAS). Monte Alto, SP, 1994.

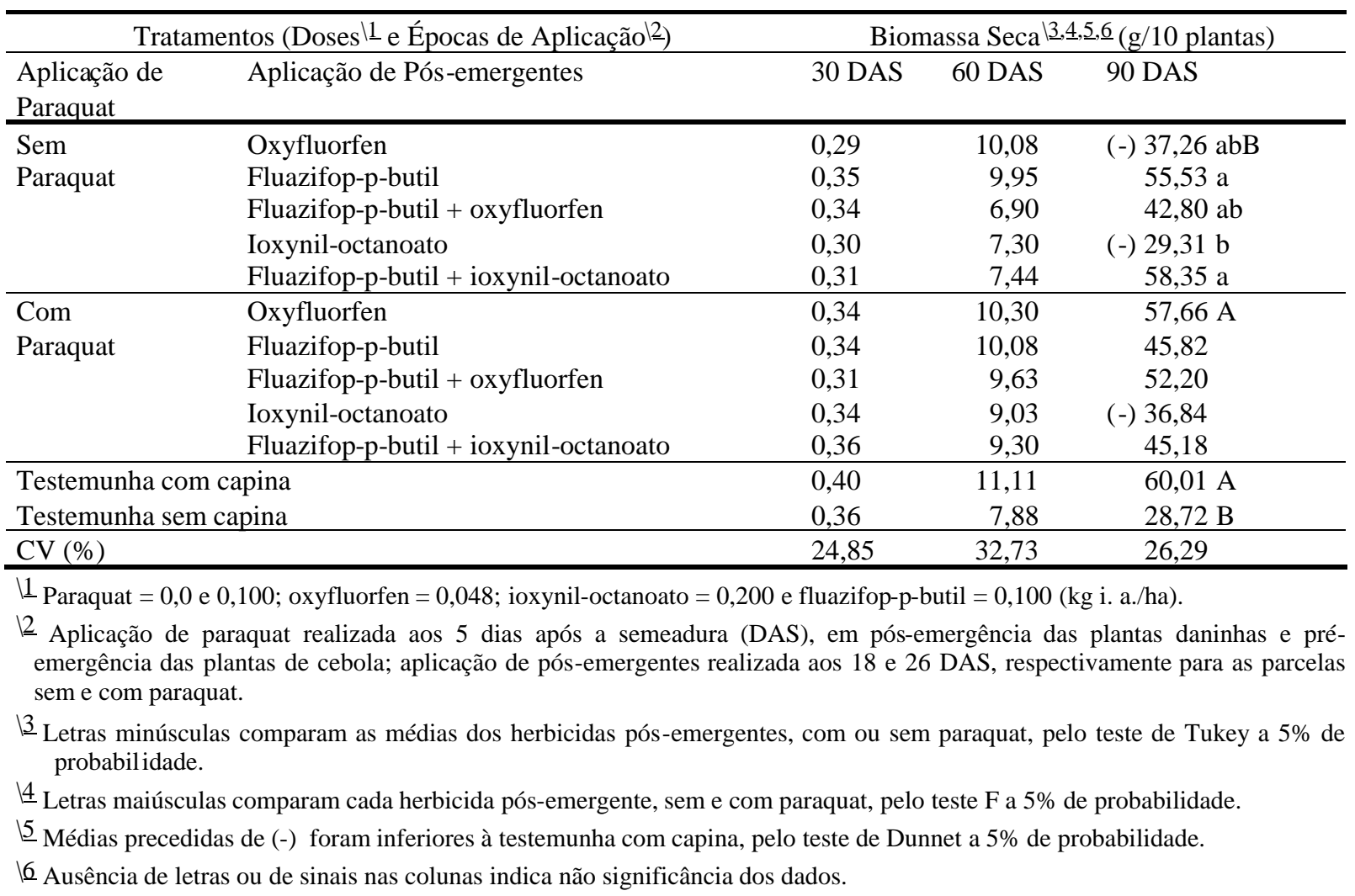

controle deficiente das gramíneas proporcionado por estes tratamentos. A maior diferença entre os tratamentos com e sem paraquat foi obtida com o oxyfluorfen aplicado isoladamente, o qual controlou eficientemente E. pilosa na presença de paraquat e foi ineficiente na ausência do mesmo. Segundo Obara (1991) essa planta daninha apesar de ser de pequeno porte epígeo, tem uma grande capacidade de perfilhamento, ocupa rapidamente o espaço, causando grande redução na produção de cebola.

Nas condições em que foi realizado este experimento pode se concluir que:

a) todas as combinações de herbicidas, nas doses avaliadas, foram bem toleradas pelas plantas de cebola, não apresentando nenhum sintoma de toxicidade aos 20 dias após aplicação, embora tenham existido diferenças na produtividade, em razão das diferenças na eficiência de controle das plantas daninhas.

b) as misturas no tanque de fluazifop-pbutil com oxyfluorfen ou com ioxynil-octanoato proporcionaram os melhores controles de $P$. oleracea, A. lividus, E. crusgalli, E. pilosa, D. horizontalis, E. indica e B. plantaginea e, também, as maiores produções de bulbos comercializáveis, independente da aplicação do paraquat sobre as plantas que emergiram antes da cebola.

c) a aplicação de paraquat, antes da emergência das plantas de cebola, foi benéfica quando o oxyfluorfen foi aplicado isoladamente. Melhorou o controle de gramíneas e aumentou a produção de bulbos.

d) nenhum dos herbicidas, aplicado isoladamente, controlou eficientemente todas as plantas daninhas. 
TABELA 5. Médias da produção total, da produção comercializável e do peso médio de bulbos comercializáveis de cebola cv 'Granex Ouro' no sistema de semeadura direta. Monte Alto, SP, 1994.

\begin{tabular}{|c|c|c|c|c|}
\hline \multicolumn{2}{|c|}{ Tratamentos (Doses ${ }^{1}{ }^{1}$ e Épocas de Aplicação ${ }^{12}$ ) } & \multirow{2}{*}{$\begin{array}{c}\text { Prod Totak } 3,4,5,6 \\
\text { (t/ha) }\end{array}$} & \multirow{2}{*}{$\begin{array}{l}\text { ProdComerc. } 13,4,5,6 \\
\text { (t/ha) }\end{array}$} & \multirow{2}{*}{$\begin{array}{l}\text { PesoMédio } 13,4,5,6 \\
\text { (g/bulbo) }\end{array}$} \\
\hline $\begin{array}{l}\text { Aplicação de } \\
\text { Paraquat }\end{array}$ & Aplicação de Pós-emergentes & & & \\
\hline Sem & Oxyfluorfen & (-) $16,2 \mathrm{cB}$ & (-) $14,9 \mathrm{cB}$ & (-) $47,9 \mathrm{~dB}$ \\
\hline \multirow[t]{4}{*}{ Paraquat } & Fluazifop-p-butil & $34,2 \mathrm{ab}$ & $33,6 \mathrm{ab}$ & $71,7 \mathrm{bc}$ \\
\hline & Fluazifop-p-butil + oxyfluorfen & & & \\
\hline & Ioxynil-octanoato & (-) $19,9 \mathrm{bc}$ & (-) $18,3 \mathrm{bc}$ & (-) $59,2 \mathrm{~cd}$ \\
\hline & Fluazifopp-butil+ ioxyni-octancato & $41,9 \mathrm{a}$ & $40,8 \mathrm{a}$ & $96,7 \mathrm{a}$ \\
\hline Com & Oxyfluorfen & 35,5 abcA & abcA & $73,5 \mathrm{abA}$ \\
\hline \multirow[t]{4}{*}{ Paraquat } & Fluazifop-p-butil & $33,9 \mathrm{bc}$ & $33,0 \mathrm{bc}$ & $81,2 \mathrm{ab}$ \\
\hline & Fluazifop-p-butil + oxyfluorfen & $49,1 \mathrm{a}$ & $48,7 \mathrm{a}$ & $91,3 \mathrm{a}$ \\
\hline & Ioxynil-octanoato & (-) $23,1 \mathrm{c}$ & (-) $22,1 \mathrm{c}$ & $(-) 65,5 b$ \\
\hline & Fluzifopp-butil+ ioxyni-octancato & $43,2 \mathrm{ab}$ & $a b$ & $91,9 \mathrm{a}$ \\
\hline \multirow{2}{*}{\multicolumn{2}{|c|}{$\begin{array}{l}\text { Testemunha com capina } \\
\text { Testemunha sem capina }\end{array}$}} & 44,9 A & & $4 \mathrm{~A}$ \\
\hline & & $13,4 \mathrm{~B}$ & $11,7 \mathrm{~B}$ & $49,8 \mathrm{~B}$ \\
\hline \multicolumn{2}{|l|}{$\mathrm{CV}(\%)$} & 23,0 & 23,6 & 14,7 \\
\hline \multicolumn{5}{|c|}{$\begin{array}{l}\text { "1 Paraquat }=0,0 \text { e } 0,100 \text {; oxyfluorfen }=0,048 \text {; ioxynil-octanoato }=0,200 \text { e fluazifop-p-butil }=0,100 \text { (kg i. a./ha). } \\
\text { ¿2 Aplicação de paraquat realizada aos } 5 \text { dias após a semeadura (DAS), em pós-emergência das plantas daninhas e pré-emergência } \\
\text { das plantas de cebola; aplicação de pós-emergentes realizada aos } 18 \text { e } 26 \text { DAS, respectivamente para as parcelas sem e com } \\
\text { paraquat. }\end{array}$} \\
\hline \multirow{2}{*}{\multicolumn{5}{|c|}{$\begin{array}{l}{ }^{B} \text { Letras minúsculas comparam as médias dos herbicidas pós-emergentes, com ou sem paraquat, pelo teste de Tukey a } 5 \% \text { de } \\
\text { probabilidade. } \\
{ }^{\sharp} \text { Letras maiúsculas comparam cada herbicida pós-emergente, sem e com paraquat, pelo teste } \mathrm{F} \text { a } 5 \% \text { de probabilidade. }\end{array}$}} \\
\hline & & & & \\
\hline \multicolumn{5}{|c|}{${ }_{6}^{5}$ Médias precedidas de (-) foram inferiores à testemunha com capina, pelo teste de Dunnet a $5 \%$ de probabilidade. } \\
\hline
\end{tabular}

\section{LITERATURA CITADA}

BANZATTO, D.A., KRONKA, S,N. Experimentação agrícola. 2 ed., Jaboticabal: FUNEP, 1992. 247 p.

BRASIL. Portaria $\mathrm{n}^{\mathrm{o}} 6305$ de 15 de dezembro de 1975. Aprova as normas de identificação, qualidade e embalagem de cebola. Decreto 8211, de 14 de agosto de 1978. Diário Oficial, Brasília, Seção 1, p.7425-27, 1982.

FERREIRA, L.R. Eficácia e seletividade de herbicidas para a cultura da cebola (Allium cepa L.) em semeadura direta. Jaboticabal: UNESP, 1997, 130 p. Tese
(Doutorado em Agronomia) - Universidade Estadual Paulista, 1997.

LEAL, F.R. Efeitos da profundidade, da densidade de semeadura direta $\mathrm{e}$ do controle químico em pós-emergência das plantas daninhas na produção de cebola (Allium cepa L.). Jaboticabal: UNESP, 1984. 87p. Dissertação (Mestrado em Produção Vegetal) - Universidade Estadual Paulista, 1984.

LEAL, F.R., CHURATA-MASCA, M.G.C., DURIGAN, J.C., PITELLI, R.A. Controle de plantas daninhas na semeadura direta de 
cebola (Allium cepa L.). Rev. Ceres, Viçosa, v.32, n.179, p.63-74, 1985.

OBARA, S.T. Efeitos da época e extensão do período de convivência das plantas daninhas sobre a produção da cultura da cebola (Allium cepa L.). Jaboticabal: UNESP, 1991. 89p. Monografia (Apresentada à Faculdade de Ciência Agrárias e Veterinárias, UNESP, para graduação em Agronomia) - Universidade Estadual Paulista, 1991.

OLIVEIRA, J.M.F. Efeito de períodos de competição de plantas daninhas na produção de cebola (Allium cepa $\mathbf{L}$.) implantada através de semeadura direta. Lavras: ESAL, 1989. 73 p. Dissertação (Mestrado em Fitotecnia) - Escola Superior de Agricultura de Lavras, 1989.

OLIVEIRA JUNIOR , R.S. Controle de plantas daninhas e seletividade do oxyfluorfen e ioxynil-octanoato para cebola (Allium сера L.) em semeadura direta. Viçosa: UFV, 1994. 111p. Dissertação (Mestrado em Fitotecnia) - Universidade Federal de Viçosa, 1994.
OLIVEIRA JUNIOR, R.S., SILVA, J.F., FERREIRA, L.R., REIS, F.P. Sensibilidade de cultivares de cebola (Allium cepa L.) implantados por semeadura direta ao oxyfluorfen aplicado em diferentes estádios de desenvolvimento da planta. Rev. Ceres, Viçosa, v.251, n.44, p.1-16, 1997.

OLIVEIRA JUNIOR, R.S., SILVA, J.F., FERREIRA, L.R., REIS, F.P. Tolerância de três cultivares de cebola ao ioxyniloctanoato e oxyfluorfen em semeadura direta. Bragantia, v.54, n.2, p.335-42. 1995.

PITELLI, R.A. Efeitos de períodos de convivência e de controle das plantas daninhas no crescimento, nutrição mineral e produtividade da cultura da cebola (Allium cepa L.) Jaboticabal: UNESP, 1987. 140 p. Tese (Livre Docência) - Universidade Estadual Paulista, 1987.

SHADBOLT, C.A., HOLM, L.G. Some quantitative aspects of weed competition in vegetable crops. Weeds, Urbana, v.4, n.2, p.111-23, 1956. 